\title{
Tense and Connective Constraints on the Expression of Causality
}

\author{
Pascal Amsili \\ TALANA, \\ Université Paris 7 \\ 2, pl. Jussieu, case 7003 \\ F-75251 PARIS Cedex 05, France \\ Pascal.Amsilielinguist. jussieu.fr
}

\author{
Corinne Rossari \\ Université de Genève, \\ Faculté des Lettres, dpt de Linguistique \\ 2, rue de Candolle, \\ CH-1211 GENEVE 4, Switzerland \\ Corinne. Rossarielettres . unige.ch
}

\begin{abstract}
Starting from descriptions of French connectives (in particular "donc"-therefore), on the one hand, and aspectual properties of French tenses passé simple and imparfait on the other hand, we study in this paper how the two interact with respect to the expression of causality. It turns out that their interaction is not free. Some combinations are not acceptable, and we propose an explanation for them. These results apply straightforwardly to natural language generation: given as input two events related by a cause relation, we can choose among various ways of presentation (the parameters being (i) the order, (ii) the connective, (iii) the tense) so that we are sure to express a cause relation, without generating either an incorrect discourse or an ambiguous one.
\end{abstract}

\section{Introduction}

The work reported in this paper aims at determining which constraints hold on the interaction between the expression of causality (with or without connective) and aspectual properties of the eventualities and of the tenses used to express them. As a matter of fact, it turns out that, at least in French, the choice of one of the two tenses passé simple (PS) or imparfait (IMP) is not neutral with respect to the expression of causality, in particular realised by means of the connective "donc" (therefore).

It has been observed that even when concerned only with temporal localisation, it is not enough to characterize tenses if one do not take into account the effects of discourse relations between eventualities ${ }^{1}$ : (1a-b) (Molendijk, 1996); it has also been observed that the use of the

\footnotetext{
${ }^{1}$ We use the term eventuality to refer to either events, states or processes, as is traditional since (Bach, 1981).
}

connective "donc" is itself subject to various acceptability constraints (1c-d) (Jayez, 1998).

(1) a. Paul attrapa une contravention. \# Il roulait avec plaisir Paul got fined. He was driving with pleasure $^{2}$

b. Paul attrapa une contravention. Il roulait trop vite Paul got fined. He was driving too fast

c. La branche cassa. \# Paul tombait donc dans le vide The branch broke. Paul was therefore falling down

d. Sa première demande fut refusée. Il en rédigeait donc une autre His first application was refused. He was therefore writing another one

Our objective in this paper is twofold: we want to study systematically the interaction between the various parameters we have mentionned, in order to provide a general explanation for the acceptabilities that have been observed, and we also want these explanations be formulated in terms of "conditions of use", so that our results are exploitable for text generation. As a matter of fact, the choice of an appropriate form to express a cause relation between events has proved a non trivial problem (Danlos, 1987; Danlos, 1998). Two parameters have been identified as playing an important role: first, the order of presentation (cause before consequence, or the contrary), and second,

\footnotetext{
${ }^{2}$ The contrast between PS and IMP is only roughly parallel to that between simple past and past progressive: e.g., the translation into French of a simple past can be either PS or IMP. We translate systematically IMP into past progressive, even when the glose does not have the same aspectuo-temporal properties as the French original. Similarly, "therefore" is only roughly equivalent to "donc".
} 
the presence (or absence) of a connective ${ }^{3}$. The examples we deal with in this paper suggest that tenses, at least in French and in particular the choice between PS and IMP must also be taken into account.

The assumptions we make for this work are the following.

We assume the view on discourse adopted within the SRDT framework (Asher, 1993): in a coherent discourse, sentences are linked by discourse relations, which help finding anaphor antecedents, computing temporal localisations, etc. Here, we are concerned only with two discourse relations, both involving causality. We call the first one result, as in (Lascarides and Asher, 1993), it holds between two sentences when the main eventuality of the first one is the cause of the main eventuality of the second one. We assume here a very open notion of causality that we don't want to refine. ${ }^{4}$ We call the other one explanation, it holds between two sentences when the cause is presented after its consequence, thus playing an explanation role for the first sentence. This configuration in interaction with "donc" has been studied in (Rossari and Jayez, 1997) where it is called "causal abduction".

We adopt as a basis for the description of IMP the proposal made in the DRT framework (Kamp and Rohrer, 1983; Kamp and Reyle, 1993), amended with proposals made in French literature, in particular concerning the anaphoric properties of this tense (TasmowskiDe Ryck, 1985; Vet and Molendijk, 1985; Molendijk, 1994).

At last, we adopt the description of the connective "donc" which is elaborated, in terms of conditions of use and semantic effects, in (Jayez and Rossari, 1998).

We start by considering discourses where a cause is presented after its consequence (i.e., an explanation discourse relation should hold). We observe that a PS-IMP sequence is sufficient to achieve the explanation effect, but that this sequence is constrained by the type of causality

\footnotetext{
${ }^{3}$ (Danlos, 1988) shows the influence of many others parameters, like the voice active vs. passive, the presence of a relative clause, etc.

${ }^{4}$ For instance, we assume that causality holds between a branch breaking and John's falling (direct), but also between Jean's repairing his car and his driving it (indirect).
}

at stake. We also notice that connectives do not seem to interfere with tenses in this case $(\S 2)$.

We then examine discourses where the cause is presented before the consequence. In the absence of connective, we observe that none of the acceptable forms automatically convey causality (§ 3.1). With the connective "donc", causality is imposed by the connective, but in its turn it brings new constraints $(\S 3.2)$. For each set of examples, we provide a general explanation and draw conclusions for text generation.

\section{Consequence-Cause Configuration}

\subsection{Data}

Even if a causality (the second sentence introducing the cause of the first one) is pragmatically possible in all these examples, we observe that a sequence PS-PS imposes in French a temporal sequence interpretation: in all the examples (3), the main eventuality of the second sentence is interpreted as temporally located after the one of the first sentence, and this is strictly incompatible with a causality, where cause must precede its effect. Notice that here PS in French behaves differently from simple past in English. ${ }^{5}$

(3) a. Jean tomba. La branche cassa Jean fell. The branch broke

b. Jean attrapa une contravention. Il roula trop vite Jean got fined. He drove too fast

c. Marie cria. Jean lui cassa la figure Marie cried. Jean hit her

d. Jean prit sa voiture. Il la répara Jean took his car. He repaired it

e. Jean se salit. Il répara sa voiture Jean dirtied himself. He repaired his car

Now, if one chooses, with the same order of presentation, the tense combination PS-IMP, the causality effect is easily achieved. This is the case for the examples (4).

(4) a. Jean attrapa une contravention. Il roulait trop vite Jean got a fine. He was driving too fast

b. Marie cria. Jean lui cassait la figure Marie cried. Jean was hitting her

${ }^{5}$ The translation of the ambiguous example (2a) (Lascarides and Asher, 1993) is not ambiguous in French where no causal interpretation is available (2b).

(2) a. John fell. Max pushed him. b. Jean tomba. Max le poussa. 
However, this choice is not always applicable, since it can give rise to unacceptable forms: (5) are either incorrect, or do not convey causality.

(5) a. \# Jean tomba. La branche cassait Jean fell. The branch was breaking

b. \# Jean prit sa voiture. Il la réparait Jean took the car. He was repairing it

The connective "donc" can be used in such configurations, without changing acceptability. The denoted relation in this case concerns both the epistemic level (attitudinal) and the descriptive level (propositional) (Jayez and Rossari, 1998). We consider in this paper only uses of "donc" where the epistemic level does not change fondamentaly the relation. ${ }^{6}$

\subsection{Discussion}

We think that these acceptabilities can be explained if one takes into account two principles: one concerns causality itself in connection with aspectuality, the other concerns the French IMP's ability to act as an aspectual operator.

\subsubsection{Causality}

To account for the contrast between (4) and (5), we have to be more specific about the way causality can hold between eventualities. Let us assume $e_{1}$ is the cause of $e_{2}$. We can distinguish two cases:

1. $e_{1}$ has to be completed to be the cause of $e_{2}$. For instance, the breaking of the branch has to be completed before Jean can fall; Jean's car has to be repaired before he can drive it.

2. it is not necessary for $e_{1}$ to be completed to be the cause of $e_{2}$. For instance, starting to repair the car is enough to be the cause of one's getting dirty; driving too fast is enough to get a fine, independantly of the completion of $e_{1}$.

We call the first case accomplished causality. Notice that this distinction is independant of the aspectual class of the verb describing the eventuality. It is only a matter of world knowledge.

\footnotetext{
"In this configuration, "car" (for) is the non marked connective. Its introduction does not change notably the acceptability jugements, we leave the examination of its specific constraints for another study.
}

\subsubsection{IMP as an aspectual operator}

One of the most important properties of IMP is that it imposes an imperfective (durative, non accomplished) view on the eventuality (Vet, 1980). The way this effect operates can be described the following way, assuming the usual partition of predicates into the four Vendler's (1967) aspectual classes.

States, activities These eventualities, either homogenious (states) or not (activities), are non terminative, in the sense that they do not have a natural term (end) (e.g., to know the truth-state, to run-activity). Then IMP is entirely compatible, thus have no particular effect.

Achievements, accomplishments These are characterised by the existence of a natural term. The imperfective point of view brought by IMP imposes a change of point of view on the term of the eventuality.

As for accomplishments, we can assume that they can be decomposed into several stages, according to (Moens and Steedman, 1988): first a preparatory phase, second a culmination (or achievement) (we are not concerned here with the result state). We can then say that IMP refers only to the preparatory phase, so that the term of the eventuality loses all relevance. This explains the so-called imperfective paradox: it is possible to use IMP even though the eventuality never reaches its term:

(6) a. Il traversait la rue quand la voiture l'a écrasé

He was crossing the street when the car hit him

b. * Il traversa la rue quand la voiture l'a écrasé

He crossed the street when the car hit him

As for achievements, we can assume that they are reduced to a culmination. Then IMP can only be interpreted by stretching this culmination, transforming a fundamentaly punctual event into a process or activity. Then there is no more natural term for such a stretched event.

\subsubsection{Causality and aspect}

So, when we have a non accomplished causality, i.e., when it is possible to state the cause rela- 
tion as soon as the eventuality has started, then IMP does not impose further constraint, and the sequence PS-IMP is always correct, and conveys the appropriate causality effect. This is the case for the examples $(4,7)$, where an explanation discourse relation is infered.

(7) Jean se salit. Il réparait sa voiture Jean got dirty. He was repairing his car

On the contrary, if we have an accomplished causality, i.e. if the cause event has to be completed to be a cause for the other event, then IMP is never possible, for even with terminative eventualities (the branch breaking, fixing the car), it has the effect of blocking the terminativity, and a causal interpretation is no longer possible (5).

The contrast ( 8 ) can thus be easily explained: in $(8 \mathrm{a})$, we have a lexically punctual event, made durative by the IMP. But going through a red light has to be completed to risk a fine; in (8b), we have an activity, and it is sufficient to have started it to risk a fine.

(8) a. * Jean attrapa une contravention.

Il brûlait un feu rouge

Jean got a fine. He was going through a red light

b. Jean attrapa une contravention.

Il brûlait les feux rouges

Jean got a fine. He was going through the red lights

\subsection{Application}

The consequences of the observations and the hypotheses made earlier, when it comes to text generation, are the following:

If one wants to present two eventualities related by a cause relation, so that the consequence is presented before the cause, leading to an explanation interpretation of the discourse, one should obey the following principles:

1. A PS-PS combination is not appropriate.

2. A PS-IMP combination conveys causality, provided that we have a non accomplished causality. Otherwise, the PS-IMP combination is not valid.

We should note again that these constraints are not lexical, in the sense that they do not rely on aspectual classes, but rather on world knowledge.

\section{Cause-Consequence Configuration}

Let us now turn to the other mode of presentation, namely the one where cause is presented before its consequence. We first consider cases without connectives, and see that good acceptabilities go along with higher ambiguity: correct example do not always convey causality (§ 3.1). Then we consider the use of the connective "donc", and observe that it changes the acceptabilities (§ 3.2).

\subsection{Without connective}

\subsubsection{Data}

The first observation is that it is possible to use a PS-PS sequence. In the absence of other discourse clues, such a sequence is interpreted in French as a temporal sequence relation. Such a temporal interpretation is compatible with, but of course does not necessary imply, a cause relation.

(9) a. La branche cassa. Il tomba dans le vide The branch broke. He fell down

b. Paul vit sa demande rejetée. Il en rédigea une autre

Paul's application was rejected.

He wrote an other one

c. Il fut nommé PDG.

Il contrôla tout le personnel

He was appointed chairman.

He had control over the whole staff

d. Il appuya sur la détente. Le coup partit. He pressed the trigger. The gun went off

Changing the PS-PS sequence into a PS-IMP changes only marginally the acceptabilities, and the same observation as before holds: these discourses do not necessarily imply causality.

(10) a. La branche cassa.

Il tombait dans le vide The branch broke. He was falling down

b. Paul vit sa demande rejetée. Il en rédigeait une autre Paul's application was rejected. He was writing an other one

c. Il fut nommé PDG. Il contrôlait tout le personnel He was appointed chairman.

He was having control over the whole staff

d. ? Il appuya sur la détente.

Le coup partait.

He pressed the trigger.

The gun was going off 
For instance, (10b-c) can also be interpreted as background discourses, where the IMP of the second sentence is seen as introducing a background situation holding before and after the event introduced in the first sentence. This interpretation, often given as the default one for IMP-PS sequences (Kamp and Rohrer, 1983), is nevertheless only available when world knowledge does not exclude it (10a). In any case, such an interpretation is incompatible with a causal interpretation.

\subsubsection{Discussion}

So it turns out that PS-IMP sequences can have in general two interpretations: one where the two events follow each other, and this interpretation is thus compatible with a causality interpretation, and another one where the eventuality described by the IMP sentence overlaps with the event given before.

This can be explained if one assumes the operation of IMP as described in (Molendijk, 1994), in a DRT framework, itself inspired by (Reichenbach, 1947).

One of the features of IMP is to state the simultaneousness of the eventuality described with some reference point (henceforth Rpt), located in the past of the speech time. This operation can be called anaphoric, since IMP needs some other point given by the context. This is clearly what happens with the background effect. But it has also been shown, in particular by Tasmowski-De Ryck (1985), that there are some uses of IMP (called imparfait de rupture"breaking IMP") which are not strictly anaphoric, in the sense that the Rpt cannot be identified with any previously introduced event. Rather, it seems that such uses of IMP strongly entail the existence of an implicit Rpt, distinct from the events already introduced. It is also observed that this ability of IMP to bring with it a Rpt is constrained. In particular, there must be a way to connect this Rpt to the other eventualities of the discourse. Molendijk (1996) shows that this connection can be a causal relation. It has also been observed that an implicit Rpt is always temporally located after the last event introduced. So this is compatible with a causality interpretation.

\subsubsection{Application}

From a text generation point of view, the observations we have just made cannot be easily ex- ploited: obviously, in a Cause-Consequence configuration, all the tense combinations we have seen are not informative enough, and cannot be used, if one wants to guarantee that the concept of causality is conveyed by the discourse.

It is thus necessary to be more explicit, for instance by adding a connective. This is what we are concerned with in the next section.

So, if we leave apart the PS-PS sequence, what we have seen so far in $\S 2$ is that the tense combination is sufficient to convey a causality relation in Consequence-Cause configurations, and then the connectives do not impose further constraints and do not change what is conveyed. The situation in this section $(\S 3)$ is in a way symetrical: in a Cause-Consequence configuration, the tense configuration is not sufficient, so that adding a connective is necessary. But, as we see in the next section, there are further constraints on the connectives.

\subsection{With the connective "donc"}

\subsubsection{Data}

One can observe that "donc" is perfectly compatible with PS-PS sequences like the ones in (9). What is more surprising is that adding "donc" to the PS-IMP sequence examples we have seen (10) clearly changes the acceptabilities:

\section{(11) a. ?? La branche cassa. Il tombait donc dans le vide The branch broke. He was therefore falling down \\ b. Paul vit sa demande rejetée. Il en rédigeait donc une autre Paul's application was rejected. He was therefore writing another one \\ c. Il fut nommé PDG. Il contrôlait donc tout le personnel He was appointed chairman. He was therefore having control over the whole staff \\ d. ?? Il appuya sur la détente. Le coup partait donc. He pressed the trigger. The gun was therefore going off}

The clearer contrast concerns cases where the second sentence contains an activity verb. In such cases, the introduction of "donc" leads systematically to bad sentences. On the contrary, it seems that "donc" is always compatible with state and accomplishment verbs.

As for achievements, it seems that the introduction of "donc" also yields bad sentences, but 
it is worth noting that the simple sequence PSIMP without connective is already slightly problematic, as we have seen in (10d). We come back to this point later.

\subsubsection{Discussion}

We are not yet able to provide a completely elaborated explanation for these observations. What we propose here is a list of possible answers, suggested by more fine-grained considerations on data.

Note however that from the previous observation we can draw the principle that we can generate sentences in a Cause-Consequence configuration, with a PS-IMP sequence, and the connective "donc" but the aspectual class of the verb has to be taken into account. It leads to acceptable sentences only with accomplishments and states.

It is clear that aspectual classes play a role, which is not surprising, and this is the reason why all our example lists comprise each time one verb from each aspectual class.

The most problematic contrast concerns the difference between activities and accomplishments. The connective "donc" seems to work very well with accomplishments and very bad with activities, even though accomplishments can be seen as composed of an activity followed by a culmination. One possible explanation could rely on the observation that the result relation brought by "donc" holds not at the propositionnal level, not even at the aspectual (i.e., point of view on events), but rather at an attitudinal level (Rossari and Jayez, 1997). Besides, one can observe that what distinguishes activities and accomplishments is not the nature itself of the eventuality, but rather the fact that one expects/considers the culmination of it in one case and not in the other. So this can be seen as a difference of (propositional) attitude over the eventualities. We are presently working on the elaboration of a proposal based on this viewpoint. It is also worth observing that the temporal interval that lies between a cause and its consequence might play a role, as suggested by (Jayez, 1998), especially for this contrast between activities and accomplishments.

As for achievements, we have already noted that their compatibility with IMP is not entirely established, for reasons coming from the punctual nature of achievements. It is also worth noting that there is an affinity between achievements and "imparfait de rupture" (TasmowskiDe Ryck, 1985). Of course, as suggested by its name, such use of IMP introduces a sort of break in the discourse, which is of course compatible with causality, but might not be compatible with the way "donc" operates, requiring a strong connection between two utterances.

\section{Conclusion}

Summary We summarize our observations in the table 1. We consider in this table all the possible configurations one has when the three following parameters vary.

1. Order of presentation: $e_{1}$ before $e_{2}$ or the other way around (assuming $e_{1}$ is the cause of $\mathrm{e}_{2}$ ).

2. Presence of a connective "donc" or "car". ${ }^{7}$

3. Use of PS or IMP.

Table 1: Ways of expressing "CAUSE $\left(\mathrm{e}_{1}, \mathrm{e}_{2}\right)$ "

\begin{tabular}{|c|c|c|}
\hline When & D. R. & How \\
\hline \multirow[t]{4}{*}{ Always } & res & $\mathrm{e}_{1}^{\mathrm{pS}} \cdot \overline{\text { Donc }} \mathrm{e}_{2}^{\overline{p s}}$ \\
\hline & $\exp$ & $e_{2}^{\text {pss }} \cdot \operatorname{Car}^{7} e_{1}^{p s}$ \\
\hline & suc & $e_{1}^{\text {ps }} \cdot e_{2}^{\text {ps }}$ \\
\hline & ntr & $e_{1}^{p s} \cdot e_{2}^{i m p}$ \\
\hline Sometimes C1 & res & $e_{1}^{p s}$. Donc $e_{2}^{\text {pMp }}$ \\
\hline $\mathrm{C} 2$ & $\exp$ & $e_{2}^{p s} \cdot\left(\operatorname{Car}^{7} / \emptyset\right) e_{1}^{\mathrm{imp}}$ \\
\hline \multirow[t]{3}{*}{ Never } & - & $e_{1}^{\text {IMP. }}$ ( Donc $\left./ \emptyset\right) e_{2}^{p s}$ \\
\hline & - & $e_{2}^{p s} \cdot e_{1}^{p s}$ \\
\hline & - & $\mathrm{e}_{2}^{\mathrm{MP} P} \cdot\left(\operatorname{Car}^{7} / \emptyset\right) \mathrm{e}_{1}^{p \mathrm{~s}}$ \\
\hline
\end{tabular}

Among the combinations, some are always possible (which does not mean they always convey causality), some are never possible, that is, either uninterpretable or incompatible with causality. Some are sometimes possible, depending on various constraints as shown in this paper. Notice that we mention in this table some configurations we have not considered so far, namely configurations with an IMP-PS sequence.

\footnotetext{
7 As we have already said, we are only concerned in this paper with "donc" and mention "car" only for the sake of completeness.
} 
We mention them here only for the sake of completeness, since they can never be used to express causality.

The second column of the table gives the discourse relation associated with each configuration. In some cases, it is a cause relation, either in one direction (result-res) or in the other (explanation-exp). The other cases are compatible with a cause relation, without conveying it, which is noted in the table as "suc" (for temporal succession) or "ntr" (neutral-for ambiguous cases between background or temporal succession).

Conclusion This paper shows that the interaction of constraints coming from tenses and connectives is rather delicate to characterize, even in the limited domain of the expression of causality. It also shows, however, that it is possible to draw from the linguistic characterisation of these enough principles to be able to generate discourses conveying causality with good guaranties on the achieved effect, and control over the influence of tenses often neglected in this respect.

We are presently studying the treatment of other connectives, and the extension to other tenses.

\section{Acknowledgments}

We wish to thank Laurent Roussarie, as well as the anonymous reviewers for their helpful comments on earlier versions of this paper.

\section{References}

Nicholas Asher. 1993. Reference to Abstract Objects in Discourse. Kluwer Academic Publisher.

Emmon Bach. 1981. On time, tense and aspect: An essay on english metaphysics. In Peter Cole, editor, Radical Pragmatics, pages 6281. Academic Press, New York.

Laurence Danlos. 1987. The Linguistic Basis of Text Generation. Cambridge University Press.

Laurence Danlos. 1988. Connecteurs et relations causales. Langue Française, 77:92-127.

Laurence Danlos. 1998. Causal relations in discourse: Event structure and event coreference. In Pierrette Bouillon and Frederica Busa, editors, Studies within the Generative Lexicon Framework. CUP Press. to appear.
Jacques Jayez and Corinne Rossari. 1998. La portée sémantique d'un connecteur pragmatique. Cahiers de l'Institut de Linguistique de Louvain. to appear.

Jacques Jayez. 1998. Les approches formelles de l'enchaînement des temps. L'exemple de la SDRT. Manuscript.

Hans Kamp and Uwe Reyle. 1993. From discourse to logic. Kluwer Academic Publisher.

Hans Kamp and Christian Rohrer. 1983. Tense in texts. In R. Bäuerle, C. Schwarze, and A. von Stechow, editors, Meaning, Use and Interpretation of Language, pages 250-269. De Gruyter, Berlin.

Alex Lascarides and Nicholas Asher. 1993. Temporal interpretation, discourse relations and commonsense entailment. Linguistics and Philosophy, 16(5):437-493.

Marc Moens and Marc Steedman. 1988. Temporal ontology and temporal reference. Computational Linguistics, 14(2):15-28.

Arie Molendijk. 1994. Tense use and temporal orientation: the 'passé simple' and 'imparfait' of french. In C. Vet and C. Vetters, editors, Tense and Aspect in Sentence and Discourse, pages 21-47. De Gruyter.

Arie Molendijk. 1996. Anaphore et imparfait : la référence globale à des situations présupposées ou impliquées. Cahiers Chronos, 1:109-123.

Hans Reichenbach. 1947. Elements of symbolic logic. McMillan, New York.

Corinne Rossari and Jacques Jayez. 1997. Connecteurs de conséquence et portée sémantique. Cahiers de Linguistique Française, 19:233-265.

Liliane Tasmowski-De Ryck. 1985. L'imparfait avec et sans rupture. Langue Française, 67:59-77.

Zeno Vendler. 1967. Linguistics and Philosophy. Cornel University Press, Ithaca, N.Y.

Co Vet and Arie Molendijk. 1985. The discourse functions of past tenses of french. In V. Lo Cascio and C. Vet, editors, Temporal Structure in Sentence and Discourse, pages 133-159. Foris.

Co Vet. 1980. Temps, aspect et adverbes de temps en français contemporain. Droz, Genève. 